\title{
La música de salón en el Zacatecas decimonónico
}

\section{Salon music in Zacatecas in the 19th century}

\author{
SÁNCHEZ-USÓN, María José, JUAN-CARVAJAL, Mara Lioba y VDOVINA, María
}

Universidad Autónoma de Zacatecas

ID $1^{\text {er }}$ Autor: María José, Sánchez-Usón / ORC ID: 0000-0002-3409-4055, Researcher ID Thomson: S-7908-2018, CVU CONACYT ID: 432522

ID $1^{\text {er }}$ Coautor: Mara Lioba, Juan-Carvajal / ORC ID: 0000-0001-6968-3813, Researcher ID Thomson: P-7756-2016, CVU CONACYT ID: 216443

ID $2^{\text {er }}$ Coautor: María, Vdovina / ORC ID: 0000-0001-6656-0789, Researcher ID Thomson: S-7917-2018

DOI: $10.35429 / J E T .2020 .12 .4 .1 .12$

Recibido: 03 de Septiembre, 2020; Aceptado 27 de Diciembre, 2020

\section{Resumen}

En México, en la primera mitad del siglo XIX, la aspiración de crear una música distinta, independiente de la que se había cultivado en siglos anteriores, no logra proponer ni implementar todavía una nueva estética musical que borre las huellas de lo europeo, sino que, estancados en un paréntesis sin apenas creaciones originales propias, los compositores y los intérpretes importan obras extranjeras o se inspiran en estilos y trabajos ya existentes, dando como resultado partituras fáciles, superficiales, demandadas para el consumo de un público burgués que impondrá un gusto trivial, abocado solamente al aprendizaje de un instrumento o al simple entretenimiento social, como bien se constata en las composiciones de la llamada "música de salón". No será hasta las últimas décadas del siglo XIX que emerja una idiosincrasia musical mexicana expresada en la obra, de mayor calidad y mérito, de destacados maestros nacionales. En tal proceso Zacatecas no quedó al margen.

Música de salon, Zacatecas, Romanticismo

\begin{abstract}
In Mexico, in the first half of the 19th century, the aspiration to create a different music, independent of the one that had been cultivated in previous centuries, still fails to propose or implement a new musical aesthetic that erases the traces of the European, but rather, stagnates in a parenthesis with hardly any original creations of its own, composers and performers import foreign works or take inspiration from existing styles and works, resulting in easy, superficial scores, in demand for the consumption of a bourgeois public that will impose a trivial taste, destined only to the learning of an instrument or to simple social entertainment, as can be seen in the compositions of the so-called "salon music". It wasn't until the last decades of the 19th century that a Mexican musical idiosyncrasy emerged, expressed in the work, of greater quality and merit, of outstanding national masters. In this process, Zacatecas was not left out.
\end{abstract}

Salón music, Zacatecas, Romanticism

Citación: SÁNCHEZ-USÓN, María José, JUAN-CARVAJAL, Mara Lioba y VDOVINA, María. La música de salón en el Zacatecas decimonónico. Revista Teoría Educativa. 2020. 4-12: 1-12

\footnotetext{
* Correspondencia del Autor (Correo electrónico: sanchez-usonmj@uaz.edu.mx)

$\dagger$ Investigador contribuyendo como primer autor.
} 


\section{Introducción}

"Hay música que sugiere desenfadados banquetes, rojos labios, rojo vino". Ramón López Velarde (2013, p. 43).

Adaptando a los presentes intereses investigativos la representativa frase "El siglo XIX inventó la música española", la cual puede leerse en la introducción del quinto volumen de la obra colectiva Historia de la música en España e Hispanoamérica, dedicado al siglo XIX (Carreras, 2018), bien puede decirse que la decimonónica centuria hizo lo propio respecto de la música mexicana, y por ende zacatecana. En el complejo e inestable proceso de construcción de una identidad cultural en el México postcolonial, la música se va a caracterizar por fusionar las corrientes transnacionales con las tradiciones locales, lo cual dará como resultado un nacionalismo híbrido, que, no obstante, significaría un avance considerable en el desarrollo identitario del país, aunque, al mismo tiempo, una rémora respecto de la evolución musical occidental.

En la primera mitad del siglo XIX la aspiración de crear una música distinta, independiente de la que se había cultivado en siglos anteriores, no logra proponer ni implementar todavía una nueva estética musical que borre las huellas de lo europeo, sino que, estancados en un paréntesis sin apenas creaciones originales propias, los compositores y los intérpretes importan obras extranjeras o se inspiran en estilos y trabajos ya existentes, dando como resultado partituras fáciles, superficiales, demandadas para el consumo de un público burgués que impondrá un gusto trivial, abocado solamente al aprendizaje de un instrumento o al simple entretenimiento social, como bien se constata en las composiciones de la llamada "música de salón". No será hasta las últimas décadas del siglo XIX que emerja una idiosincrasia musical mexicana expresada en la obra, de mayor calidad y mérito, de destacados maestros nacionales. En todo este tiempo, tanto en la Ciudad de México como en provincia, la experiencia compositiva e interpretativa fue la misma. Zacatecas no quedó al margen de ello. Sin embargo, la atención de musicólogos e historiadores de la música ha tendido siempre a elaborar una historiografía musical capitalina, olvidando otros lugares cuyo comportamiento cultural era, aunque en menor escala, muy similar al marcado por la urbe capital.
En este sentido, faltan más investigaciones que pongan de manifiesto, a partir de una estrategia comparativa, lo que acontecía en las pequeñas ciudades provincianas del México independiente, elaborando historiografías musicales locales, rescatando para ello partituras, críticas musicales esparcidas en las fuentes hemerográficas conservadas y todo tipo de crónicas y textos literarios coetáneos, todavía ocultos en archivos y bibliotecas públicas y privadas. Este trabajo se suma, pues, a esa necesidad con el propósito de servir de punto de partida para la elaboración, algún día, de un amplio estudio de conjunto que sobre música de salón amerita Zacatecas.

\section{Metodología}

Convencionalmente, en todo tipo de trabajos investigativos se parte de exponer y explicar un objeto de estudio elucidando la problemática que éste encierra, para lo cual se propone una idea interina que se irá comprobando mediante la aplicación de una estrategia experimental pertinente, demostrada en su eficacia, finalmente, por los objetivos y metas cumplidos y los logros obtenidos. En esta ocasión el orden de esta estructura teórica ha sido subvertido. Los resultados de una investigación musical, materializados en el estudio e interpretación de una serie de partituras zacatecanas de música de salón, algunas de ellas proporcionadas por descendientes de familiares y amigos de sus compositores, condujeron, con posterioridad, a un rastreo regresivo de estos creadores locales, así como a la averiguación de las peculiaridades, ambientes y gustos que rodeaban a unas obras que luchaban por adquirir un estilo identitario y estilístico propio, pero que seguían incluyendo todas las características distintivas de las composiciones salonescas europeas.

La descripción de esta música, bellamente provinciana, impuso, a su vez, la comparación de los gustos locales con los capitalinos y, de estos últimos con las particularidades románticas europeas, adoptadas, en todos los ámbitos del arte y la cultura, en el continente latinoamericano. 


\section{Desarrollo}

\section{México y la creación de una identidad musical}

En el siglo XIX la historia de México se desarrolla entre grandes oscilaciones. En sus primeros años, la recién conquistada libertad iba a informar todos los órdenes de la vida de un país que debía aplicarse a construir otro sistema político y económico, establecer las bases de un orden social nuevo y buscar una identidad cultural que satisficiera las múltiples y disímiles expectativas independentistas. Destrabado de la metrópoli, el país luchaba por establecer un equilibrio entre la recuperación de lo ancestral, la todavía pervivencia de los vestigios hispanocoloniales, la influencia foránea y la creación de toda una base ideológica sobre la que asentar cimientos identitarios.

En este escenario titubeante, en el que alternaban continuos cambios presidenciales con sublevaciones populares, la sociedad se resentía y acusaba esta inestabilidad inicial propia de un país en reconstrucción o, más bien, en construcción, que se expresaba en desorientación, división y descontento.

Una de las muestras de este desconcierto fue la sobrevivencia del ascendiente europeo que no desapareció, sino que se mantuvo presente en todos los órdenes de la vida y las manifestaciones culturales, ora bien permeando sólo aquellos estamentos privilegiados conformados por criollos y mestizos, excluyendo de sus consecuciones a las clases subalternas, campesinas y urbanas, y, fundamentalmente, a los grupos indígenas.

En el ámbito de la música la influencia de Europa se dejó sentir de manera destacada. La estética virreinal, cortesana y eclesial, dio paso a un criterio diferente, más laico y burgués, que generó otros estilos musicales y conformó un gusto distinto, abierto al exterior y cosmopolita, intercalado con los vestigios de lo originario y las prácticas musicales populares, en una heterogénea y compleja amalgama. A decir de la musicóloga Yolanda Moreno, México se encuentra en una situación paradójica, en la que por un lado se libera de los viejos cánones musicales coloniales, abocándose a la construcción de nuevos criterios identitarios, y, por otro, busca asimilar las novedades europeas, integrándose así en los lineamientos de la cultura occidental:
Se podría (sic) definir y resumir los desarrollos estilísticos o formales del siglo XIX mexicano como intento prolongado, a veces infructuoso o parcial, de penetrar en los grandes estilos románticos y códigos culturales europeos considerados como valores universales. Lo prueba el surgimiento de las efímeras escuelas mexicanas apoyadas alternativamente en las influencias italianas, francesas o alemanas. La música, liberada, por fin, de las antiguas exigencias estilísticas y sociales de la Colonia, se desenvolvió en un terreno difícil, minado por una falta de conocimientos básicos que durante el Virreinato se daban por descontados (Moreno, 1995, p. 55).

La promoción y el auge de la música iban de la mano de la reestructuración y apoyo a la enseñanza y la protección de las artes en general; aunque, ante los problemas prioritarios que la nueva República debía enfrentar, la instrucción artística quedó en un segundo plano de atención. Era obvio que la pobreza generalizada del territorio mexicano hacía prácticamente imposible la organización de actividades culturales y la presentación de espectáculos para todos los públicos, por lo que la práctica de las artes, y en concreto de la música, se albergó entre los estamentos sociales pudientes. En las altas esferas, y para sus integrantes, se abren academias de música, se organizan las Sociedades Filarmónicas, se conocen y difunden las obras de los compositores europeos del momento, se contratan compañías extranjeras de ópera y zarzuela, se organizan, bailes, funciones teatrales, se ofrecen conciertos y veladas musicales y se conforman orquestas típicas y bandas estatales. Así, poco a poco, aunque de modo elitista, la música iba recuperando el espacio cultural que le era propio. En este sentido, dos coyunturas favorables, distintas, una general y otra específica, aunque de alguna forma relacionadas, iban a influir de manera decidida en este proceso de despegue artísticomusical: el romanticismo y el gobierno de Porfirio Díaz.

\section{El Romanticismo en la coyuntura cultural porfirista}

Como es sabido, el movimiento romántico, iniciado en Europa a finales del siglo XVIII como reacción al clasicismo anterior, dará contenido a la mayor parte de la centuria decimonónica, imponiendo un sistema de valores, ideales, principios vitales, reglas $\mathrm{y}$ gustos diferentes e inusuales.

SÁNCHEZ-USÓN, María José, JUAN-CARVAJAL, Mara Lioba y VDOVINA, María. La música de salón en el Zacatecas decimonónico. Revista Teoría Educativa. 2020 
Las pasiones exacerbadas, la emoción, la introspección, el culto al ego, la valoración de la religiosidad, principalmente cristiana, lo espiritual y lo sobrenatural, el hallazgo de la inspiración en tiempos, tierras y culturas lejanas y exóticas, la insatisfacción vital, la melancolía, la vivencia del amor no correspondido... son algunas de las principales características románticas que permearán todo tipo de creaciones artísticas.

\section{[...] esta misma visión engendró también} un respeto a la individualidad, al impulso creador, a lo único, lo independiente, a la libertad de vivir y actuar a la luz de creencias y principios personales, no dictados, de necesidades emocionales no deformadas, al valor de la vida privada, de las relaciones personales, de la conciencia individual, de los derechos humanos (Schenk, 1983, p. 13).

Desde estos nuevos planteamientos que, por supuesto, sustentan el trabajo creativo, la figura del artista dará un vuelco vertiginoso. En adelante, éste ya no se pondrá sólo al servicio de mecenas acaudalados, ni dependerá de prebendas eclesiásticas ni de estipendios que la liberalidad de nobles y reyes le otorgue para sobrevivir, como pago de sus obras generadas generalmente por encargo. Ahora, reinventará su identidad, derivada de una nueva concepción del mundo, lo cual le deparará una posición distinta en el medio social, al que de alguna manera se debe, con el que entablará un diálogo contestatario, de rechazo a lo establecido, al espíritu burgués y al precio del arte.

De ahí el culto del artista, sea del sonido, la palabra o el color, como manifestación más elevada del espíritu siempre activo, y la imagen popular del artista en su buhardilla, desmelenado, con ojos quemantes, pobre, solitario, ridiculizado, pero independiente, libre, espiritualmente superior a los filisteos que lo atormentan (Schenk, 1983, p. 13).
No obstante, esta representación del artista romántico no es sino el literaturizado cliché que presenta a un ser que vive en la diferencia, insatisfecho y atormentado, que no se corrompe ante lo material, sacrificando una vida estable y cómoda en aras de su arte, su única y verdadera pasión.

Como movimiento de amplio alcance, el romanticismo, originado en Alemania, Inglaterra y Francia, se extendió por la totalidad del continente europeo, y de allí se desplegó por tierras americanas. En Latinoamérica

[...] le romantisme français dans un premier moment et l'espagnol plus tard fournirent les sources et les modèles les plus manifestes [...] Curieusement, l'Espagne, pourtant idéologiquement discréditée, sut mieux maintenir au XIXe siècle dans ses anciens territoires américains son prestige littéraire que le Portugal au Brésil: Larra, Espronceda et Zorrilla étaient lus et imités au moins autant, voire plus, en Amérique qu'en Espagne (Collard, 2012, p. 3) ${ }^{1}$.

Particularmente en México, las diferentes manifestaciones artístico-culturales del romanticismo surgen y se desarrollan en un momento crítico, en el que por un lado se busca una nueva identidad cultural nacional y, por otro, subsiste un "apego" a la tradición hispana, así como cierta "admiración” por lo europeo. A ello, contribuirá, en gran medida, la llegada a la presidencia de la República del general Porfirio Díaz, en 1877.

En las más de tres décadas que duró el controversial régimen del Porfiriato, que supondría un largo paréntesis de estabilidad política a costa de un régimen férreo, la expansión económica que experimentó el país, favorable en exclusiva a los poderosos, posibilitó el surgimiento de numerosas manifestaciones artísticas y culturales, en mayor medida derivadas de la influencia ejercida por las corrientes intelectuales europeas del momento, sobre todo las generadas en Francia, que se constituyeron en modelos a seguir o a imitar.

\footnotetext{
1 "El romanticismo francés al principio y el español después proporcionaron las fuentes y modelos más evidentes [...] Curiosamente, España, aunque ideológicamente desacreditada, fue más capaz de mantener su prestigio literario en el siglo XIX en sus antiguos territorios americanos que Portugal en Brasil: ISSN 2523-2509

ECORFAN® Todos los derechos reservados
}

Larra, Espronceda y Zorrilla fueron leídos e imitados al menos tanto, si no más, en América que en España". De entre estos tres países, será Francia la que, en este siglo, tendrá un mayor ascendiente en la cultura mexicana; en proporción, la influencia de Italia y España fue menor.

SÁNCHEZ-USÓN, María José, JUAN-CARVAJAL, Mara Lioba y VDOVINA, María. La música de salón en el Zacatecas decimonónico. Revista Teoría Educativa. 2020 
En el ámbito de la música, bien puede decirse que este es un periodo de auge. En tal contexto, los compositores e intérpretes nacionales asimilan sin reservas las novedades europeas, pero vinculándolas, en un novedoso y heterogéneo ejercicio de fusión, con los principios musicales tradicionales. La música constituye un elemento imprescindible en la educación de la burguesía, así como un apreciado bien cultural, deseado y favorecido por los privilegiados como objeto de placer y diversión.

Un escenario en donde se acrisoló esta preferencia fue el hogar de las familias burguesas, en las que sus miembros, principalmente las mujeres, recibían desde su infancia instrucción musical. En las casas de las clases altas había piano, considerado un elemento imprescindible "por su sonoridad, capacidad improvisatoria y notable aceptación social" (Palacios y Martín, 2017, p. 337); en su interior, en reuniones familiares y sociales, se interpretaban y cantaban tanto las obras en boga como las ya consagradas, cuyas partituras se adquirían en las editoras de música o, incluso, se encargaban al extranjero. Las implicaciones de esta práctica cultural fueron mayores de lo que cabría esperarse. Como bien sintetiza Albert Recasens Barberà:

Alrededor de este superficial pero ineludible evento social, se generó todo un complejo socio-económico que implicaba, entre otras cosas, las casas importadoras de pianos, partituras y libros de música, los afinadores de dicho instrumento, los compositores y profesores de piano, los editores e impresores de música y, finalmente, la prensa escrita que se encargó de publicitar y difundir el producto (Recasens, 2010, p. 98).

Así, la música se convirtió en un bien cultural de consumo, un objeto de mercado, una distracción y un puro divertimento, cumpliendo una nueva función social, que tuvo como consecuencia la aparición de principios estéticos diferentes, que, a nivel compositivo e interpretativo, se expresaron en la llamada "música de salón".

\section{La música salonesca}

Como su nombre indica, la música de salón o salonesca recibe su denominación de un espacio nuevo de sociabilidad que se suma a los teatros y grandes salas de concierto: el salón.
El salón, pieza principal de las casas acomodadas de la Europa decimonónica, es un reducto de habitabilidad que tanto obedece a resguardar y facilitar la unión y la intimidad de la familia que lo posee como, al "abrir sus puertas", a fomentar el encuentro y la reunión de grupos sociales más amplios, cuyos integrantes se vinculan entre sí por razones de parentesco, amistad afinidad socio-cultural o, incluso, política. Pero los privados salones familiares alternan también con otros espacios de carácter público: las salas de música de instituciones como escuelas, agrupaciones religiosas o asociaciones culturales, los bailes y los cafés, lo cual habla de un momento caracterizado por el ansia de cultura musical, la cada vez más extendida práctica asociativa y la incorporación paulatina de todo tipo de concurrentes al consumo de los bienes culturales, otrora propiedad exclusiva de las élites. $\mathrm{Al}$ respecto, $\mathrm{y}$ en relación a España, el musicólogo Emilio Casares Rodicio explica que

[...] el primer núcleo importante y el más numeroso en cantidad de la música española del $X I X$, se genera al servicio de dos instituciones, el salón y el café concierto. En torno a ellos se da una importante producción que constituye el núcleo mayor de música editada: en torno a ambos viven y se calman las ansias musicales de gran parte del público español; sirvieron para introducir en la música a amplias capas de la sociedad española y para dar a conocer gran parte de la creación musical del momento; también, en torno a ambos, se produce la música más puramente romántica, es decir, el mundo de la pequeña forma (Casares y Alonso, 1995, pp. 40 y 41 ).

En México, principalmente durante el Porfiriato, los salones aristocráticos europeos constituyeron un modelo de sociabilidad cultural a imitar por las familias burguesas mexicanas que organizaban tertulias y veladas en las que la música no podía faltar, atemperando, la mayor parte de las veces, las discusiones suscitadas alrededor de la actualidad política, los chismes sociales o el resultado de los juegos de naipes a los que asimismo, con gran entusiasmo, se entregaban los concurrentes, todo ello dentro de los límites establecidos de la "decencia" y la corrección. Ejemplificando este adecuado comportamiento en los ambientes nobiliarios madrileños durante el reinado de Isabel II, Fernando Fernández de Córdova, Marqués de Mendigorría, escribe en sus Memorias intimas: 
"no se hubieran consentido entonces, como tengo entendido se toleran ahora, otra suerte de noticias chismográficas de color subido y acompañadas de comentarios, que en aquella época se reservaban para las reuniones de hombres solos" (Cfr., Diez, 2006, p. 191)2.

El mismo ambiente de "contención" reinaba en los salones de la alta sociedad mexicana, en donde la música estaba siempre presente, adquiriendo un protagonismo central en los saraos juveniles, donde las señoritas, aunque bajo la atenta mirada de madres, abuelas o chaperones, podían tener más libertad distractiva y un decoroso protagonismo, idéntico al desempeñado en las tertulias españolas o francesas, en las que las jóvenes participaban activamente recitando poemas, cantando o tocando algún instrumento, de preferencia el piano.

De hecho, la aptitud para cantar o interpretar piezas instrumentales era considerada un aderezo imprescindible para las señoritas, que solían exhibir sus dotes interpretativas en aquellas veladas. La música adquiere importancia como elemento socializador y de proyección personal -con sus derivaciones matrimoniales-, como medio de ostentar la buena educación, sobre todo en el sexo femenino (Díez, 2006, pp. 191 y 192).

Esta demostración femenina de buena crianza y habilidades era, sin duda, un señuelo para encontrar "buenos partidos" con fines matrimoniales entre los ricos herederos que frecuentaban este tipo de soirées; pero también era la manifestación de la preponderancia social de ciertas familias, en las que "el adorno" de una esposa y unas hijas distinguidas podía influir en la categoría, respetabilidad y buena imagen de esposos y padres (Daumard, 1986, pp. 81-93). Al igual que la capital y las grandes ciudades del México independiente, Zacatecas se adhiere a las nuevas corrientes culturales y prácticas sociales imperantes en el siglo XIX. (Díaz, 2009). La música que se interpretaba en sus salones privados, aun siendo menos importante y significativa que la de los grandes compositores románticos europeos, fue una opción artística eminentemente burguesa, por lo que formó parte no sólo de un cambio creativo en el orden musical, sino igualmente en el social,

\footnotetext{
2 Tomado de Fernando Fernández de Córdova, Mis memorias intimas, Establecimiento tipográfico Sucesores de Rivadeneyra, Madrid, 1886.

ISSN 2523-2509

ECORFAN® Todos los derechos reservados
}

político y económico.

No obstante, la burguesía zacatecana, que ocupaba los principales puestos de poder en el Estado y en la capital, constituía una minoría frente a una gran mayoría social desposeída de recursos económicos e instrucción. Según la historiadora local Norma Gutiérrez Hernández, este estamento privilegiado estaba, por lo general, emparentado con familias extranjeras (Gutiérrez, 2013, p. 188). En esta esfera los varones eran los que hacían gala de posiciones relevantes al frente de cargos institucionales, como propietarios de haciendas, minas y comercios, o ejerciendo profesiones liberales. Por su parte, a las mujeres, en general, no se les adjudicaba el mismo papel: "[...] contaron con cierta instrucción, presidían el 'santuario del hogar', resolviendo cuestiones domésticas y familiares, educando y haciéndose cargo de los hijos, hijas y del marido, preocupadas por acatar el ideal femenino, por lo que parte de su educación fue el refinamiento artístico, como la música, la pintura y el baile" (Gutiérrez, 2013, p. 188).

Como podrá observarse más adelante, los músicos zacatecanos realizan una labor importante en el desarrollo de la música, fundamentalmente hacia finales del siglo XIX e incluso principios del siglo XX. Esto se debe al descuido general que existió en Zacatecas respecto a la formación artística y la proyección cultural del Estado. Las necesidades eclesiásticas propiciaron la práctica empírica de la música, por lo que muchos de estos compositores fueron, ante todo, músicos de iglesia. Con el tiempo,

[por] el favorable impulso que recibió la evolución social del Estado gracias a la progresista administración del Gobernador Francisco García Salinas, la música inició su natural evolución y a su consecuencia llegó a la ciudad, en 1843, la primera compañía de ópera italiana, cuyas representaciones constituyeron el primer gran modelo de arte lírico que guio el desarrollo artístico de los músicos zacatecanos. 
Dos años después, en 1845, vino el maestro Joaquín Luna, originario del Distrito Federal, y fundó la primera academia de música que en el Estado hubo; por último, en 1856 el gobierno se interesó por la enseñanza musical, y organizó dentro del Instituto de Ciencias, que dirigía el licenciado José María Castro, una Escuela de música, poniendo su dirección bajo la responsabilidad del maestro zacatecano Francisco Morales. A partir de esa fecha, quedó concluyentemente asegurado el progreso artístico de esta entidad federativa (Romero, 1963, pp. 14 y 15).

El desarrollo minero de Zacatecas, favorable únicamente a la economía de las grandes familias, trajo consigo una abundancia material que se evidenció, sobre todo, en las últimas décadas del siglo, en la construcción de hermosos edificios, como el primer gran teatro Coliseo, inaugurado en 1833, luego denominado Teatro Fernando Calderón (VV.AA., 1996) ${ }^{3}$, la apertura de escuelas, academias de música, y la formación de bandas y orquestas infantiles.

En esta actividad cultural, la música, abundante y heterogénea, en una hibridación de estilos europeos y locales, jugaba un destacado rol, a lo cual abonaban la existencia en la ciudad de la Imprenta de Don Nazario Espinosa, que publicaba partituras musicales, (Espinosa, 2018) y el suministro de las mismas desde las grandes casas impresoras de México, como H. Nagel y A. Wagner y Levien, en la segunda mitad del siglo. En este ambiente se sucedían los eventos musicales en los que se interpretaba música de salón, que incluía variados géneros, muchos de ellos de carácter danzario, cuyas piezas se adaptaban para piano, como polka, mazurka, schottisch, vals, contradanza, cuadrilla, etc., que, de procedencia popular, habían sido "adoptados" por el gusto aristocrático y alto-burgués para, tras lograr un gran éxito, regresar a su estamento social de procedencia. También, tuvieron gran aceptación piezas sobre momentos de óperas famosas, romanzas de zarzuela, nocturnos y serenatas... Las obras derivadas de estos géneros

\footnotetext{
${ }^{3}$ Llamado así a partir de 1850 , este Teatro, situado en la Avenida Hidalgo de la capital zacatecana, y construido con recursos recolectados entre la población, fue devastado por un incendio en 1889 y reconstruido en 1897.

4 "Las jóvenes que llevaban una vida mundana encontraban una distracción en los homenajes que se les rendían: reinaban, o ISSN 2523-2509

ECORFAN® Todos los derechos reservados
}

Habian sido creadas o dignificadas por los compositores románticos de alta categoría, hasta que se convirtieron en bienes culturales de nivel decaído que iba a vegetar y sobrevivir en las clases inferiores durante muchos decenios, cuando la música de todo el mundo ya había experimentado toda una serie de transformaciones (s. a., La música en México, $s$. d.).

En Zacatecas, este tipo de música simplificada hasta lo trivial, popularizada y agotada en su lenguaje armónico hasta el extremo, fue un elemento omnipresente como factor de divertimento social. En los salones de las familias acomodadas constituyó un medio de distracción y de expansión personal y social de muchas jóvenes ociosas, contribuyendo a darles cierto protagonismo, mantenerlas activas, y disipar su hastío habitual, al mismo tiempo que les facilitaba hacer gala de su buena educación, propia de un nivel económico holgado.

Les jeunes femmes qui menaient une vie mondaine trouvaient un dérivatif dans les hommages qui se portaient vers elles: elles régnaient, ou croyaient régner, par leur beauté ou par leurs charmes et, à quelques exceptions près, cela suffisait à les satisfaire. Plus âgées, elles cherchaient une raison d'être en organisant un salon (...). Chez elles, elles étaient souvaraines, libres d'accueillir ou de remeter les hôtes de leur choix, d'imposer ce que'elles considéraient comme les bons usages, de faire ou de défaire des réputations (Daumard, 1986, p. 89$)^{4}$.

Generalmente, las mujeres de buena cuna tocaban el piano, y no sólo aquellas pertenecientes a familias connotadas; también las de clase media poseían este costoso instrumento que pasaba en herencia de generación en generación. Al respecto, el universal escritor zacatecano Ramón López Velarde, en un breve relato de juventud titulado Los pianos, escrito el 15 de diciembre de 1913, reproduce de manera vívida la atmósfera de uno de esos salones provincianos, en donde el piano adquiere la categoría de amigo confidente, depositario de ardientes y ocultos deseos y "paño de lágrimas" de amargos desengaños femeninos:

creían reinar, por su belleza o sus encantos, y, con algunas excepciones, esto era suficiente para satisfacerlas. Con más edad, buscaban una razón de ser organizando un salón (...). En sus casas, eran soberanas, libres de recibir o rechazar a los invitados que quisieran, de imponer lo que consideraban buenos modales, de hacer o destruir reputaciones".

SÁNCHEZ-USÓN, María José, JUAN-CARVAJAL, Mara Lioba y VDOVINA, María. La música de salón en el Zacatecas decimonónico. Revista Teoría Educativa. 2020 
No voy a hablar de los pianos aristocráticos que esparcen su clasicismo sobre la concurrencia de los rumbosos recitales: caballeros relamidos que se visten de negro y damas escotadas que fingen entender la música de los maestros. No, no os hablaré de los pianos próceres. Quiero hablar de los otros, de los que coadyuvan el ensueño de las humildes doncellas que llevan su hoguera de amor en el pecho y que, en la ventana del barrio desierto, esperan la llegada de un doncel de palabras galantes... El doncel no viene, y las mozas van todavía con esperanza a arrancar al piano armonías en que parezca anunciarse el alma ausente. ¿Oís? En la calleja solitaria tiemblan notas de ingenuidad, llorosas, que hablan de poéticos males: del espanto de los niños perdidos en el bosque, de la princesa núbil que mordió una fruta con veneno y quedó encantada, de los cumplimientos de los Siete Enanos a Blanca de Nieve...

Sí, estas notas agónicas, que se desmayan a prima noche en el barrio, evocan leyendas de infancia; más ¿de dónde nace la música pueril y tristona que nos hemos parado a escuchar, yendo por la acera? Seguramente sale de la caja oscura de ese piano que se entrevé por los visillos de la ventana. Se mira también, sobre una mesa en que dibujan varios niños, un quinqué con caperuza verde. Está tocando, quizá, la hermana mayor. No ejecuta con maestría, es cierto, pero comunica a los sonidos que arranca al piano un temblor de emoción. Sí, la hermana mayor nos emociona, porque en sus melodías inseguras adivinamos un perfume de ilusión de quince años, un loco entusiasmo de cazadora de estrellas y (aquí la pena fatal) una humedad de llanto (López Velarde, 2013, p. $57)^{5}$.

No cabe esperarse en esta fémina, ni en muchas otras pianistas aficionadas, virtuosismo interpretativo alguno; el propio López Velarde así lo asegura cuando califica de "inseguras" las melodías interpretadas por su protagonista, carente en su técnica de maestría alguna; pero el piano es el vehículo indirecto por el que las encorsetadas jóvenes decimonónicas, e incluso las damas ya no tan jóvenes, externaban sus emociones, estados de ánimo, ilusiones y esperanzas, en un mundo en donde la mujer apenas podía expresarse con voz propia.

\footnotetext{
${ }^{5}$ En 1913 el poeta zacatecano Ramón López Velarde inicia la escritura de una serie de relatos cortos que publicó en el periódico potosino El Eco de San Luis, con el título general de Renglones líricos. Estos fragmentos están extraídos de la narración "Los pianos", escrita el 15 de diciembre del citado año.

La emotividad de la romántica juventud zacatecana se desbordaba no sólo al interpretar o escuchar uno de estos géneros salonescos, sino, mucho más aún, al danzarlo en los bailes públicos o privados que se organizaban en el Estado, y mayormente en la capital, con motivo de festejar alguna efeméride general o particular, momentos candentes en los que las señoritas podían aproximarse a sus parejas de baile sin manchar su reputación o sufrir censura alguna. De nuevo López Velarde, en otro de sus significativos relatos cortos, describe, de modo sensorial, la impresión que para los bailarines supone la ejecución del vals:

Ven al baile... Tus brazos sobre los míos, mi corazón vecino al tuyo... Se arrastran impotentes los compases del vals... Ahora la cadencia se entusiasma y tú y yo nos confundimos en vértigo de armonía. Somos ya una pareja aislada; las otras se quedaron a distancia. La música nos envuelve y ya no pisamos la tierra. El ritmo de las flautas encierra un poder fantástico que nos lanza por la tangente del globo a planos etéreos... El vals es interminable. Los violines se acordan con nuestras almas en fiesta. Tus pies van ahora sobre celajes, muy cerca del Zodiaco... Mas ¿qué sucede? Tu cabeza, de rizos castaños, se suelta hacia atrás. ;Ay amiga, te has desmayado entre mis brazos en el firmamento como una niña que se asoma a un abismo!

Todo es mentira, Amada; estamos en tierra firme. Que siga el vals... (López Velarde, 2013, p. 42) .

En estos fragmentos se comprueba cómo esta atmósfera cargada de pasiones contenidas e invitación al romance, la mayor parte de las veces más imaginado que real, se adhiere por completo a los lineamientos estéticos y emocionales que caracterizan al romanticismo universal.
6 Estas líneas corresponden al relato "En alas de la música", escrito por el poeta jerezano el 20 de octubre de 1913. 
La música de salón, que en el transcurso del siglo evolucionó hacia la música de divertimento en general (con ramificaciones en la música militar, la música en los cafés, la opereta y la zarzuela, la música bailable y, últimamente, el jazz) constituyó en primer término un baluarte estético contra cualquier progreso innovador; sus características musicales determinaron el gusto de la mayoría social (Mayer-Serra, 1941, p. 71).

No obstante, en el ámbito musical mexicano y zacatecano, en particular, junto a este género, aunque en menor medida, se cultivó la obra de los grandes maestros románticos europeos, la ópera italiana y la zarzuela, que garantizaban la pervivencia de un pasado musical colonial, aunque ya proyectado hacia un futuro incierto pero independiente.

\section{Compositores zacatecanos: mexicanos universales}

El siglo XIX verá la emergencia de una generación de autores que elevarán la música zacatecana de salón a una categoría no sólo nacional sino internacional. La mayoría de ellos compuso música de salón, pero también para cámara, orquesta sinfónica y bandas, agrupaciones estas últimas de gran aceptación popular que proliferaron no solamente en la capital, sino en municipios como Fresnillo y Villanueva.

En atención al año de su nacimiento, el primero de ellos fue Fernando Villalpando (1844-1902). Instrumentista de alientos y cuerdas, fue director de la Banda Municipal de la capital del Estado, maestro de música, director de orquesta y compositor. Su larga trayectoria musical le llevó a disfrutar de innumerables éxitos y su gran preocupación por la evolución musical de Zacatecas se vio coronada con el establecimiento del taller de litografía "La lira zacatecana", publicación periódica dedicada a la edición de piezas musicales. En lo concerniente a sus composiciones, es muy probable que el schottisch Primer tren, editado en su imprenta, se inspirara en el acontecimiento de la llegada a Zacatecas de este medio de transporte, el 9 de marzo de 1884. Sus Cuatro Danzas (Aurora, Cuca, Carlota, Mi chica) son piezas para piano escritas de forma independiente.
Junto a Villalpando, Genaro Codina (1852-1901) es el segundo compositor zacatecano más celebrado. Nacido en la ciudad capital, mostró ya en su infancia una clara vocación por la música, aprendiendo a tocar varios instrumentos, principalmente el arpa. Desde muy joven se dedicó asimismo a la pirotecnia, dirigiendo los fuegos artificiales que se quemaban año tras año en las fiestas patrias. En 1887, compuso una marcha para el Presidente Porfirio Díaz, quien, como muestra de agradecimiento, lo nombró Contador de la Jefatura de Hacienda en Zacatecas. Posteriormente, y por cuestiones políticas, varias veces fue a prisión, pero siempre tuvo consigo su arpa, que le servía de consuelo; con ella compuso muchas de sus obras. Entre sus amistades figuraba Fernando Villalpando, con quien compitió para componer una marcha a la ciudad de Zacatecas, reto que finalmente ganó, siendo premiado por el entonces gobernador del Estado, Jesús Aréchiga, con la suma de mil pesos.

Esta "Marcha de Zacatecas", actual himno oficial del Estado, ha sido, sin duda, la obra más popular y festejada de Codina, siendo ejecutada ininterrumpidamente desde su estreno hasta la actualidad. Esta marcha, conocida no sólo a nivel nacional, sino internacionalmente, llegó incluso a ser incluida en el repertorio musical italiano en tiempo del "Duce" Benito Mussolini. Entre las obras de Codina, además de marchas, figuran polkas, mazurkas, schottisches, valses, danzas, etc., interpretadas tanto en los Recinos culturales zacatecanos como en los salones privados.

A diferencia de G. Codina, quien fuera un exitoso aficionado a la música, Villalpando fue un músico profesional, lo que puede apreciarse en la calidad técnica de sus composiciones. No obstante, "El mérito principal de ambos radica en que se formaron, florecieron y lograron fructificar su obra, dentro del solar zacatecano, y por ello deben rotundamente a Zacatecas la evolución de su personalidad artística" (Romero, 1963, p. 15).

Ernesto Elorduy Medina (1854/551913), pianista y compositor, nació en la Villa de Guadalupe, aunque vivió en Europa durante veinte años. A su regreso a México ofreció en la sala Wagner un concierto de sus obras para piano de carácter nacionalista. Su vasta producción de música de salón fue muy aclamada, considerándosele uno de los representantes de la "danza" para piano.

SÁNCHEZ-USÓN, María José, JUAN-CARVAJAL, Mara Lioba y VDOVINA, María. La música de salón en el Zacatecas decimonónico. Revista Teoría Educativa. 2020 
Fue, también, organista de la iglesia de Santo Domingo y miembro de la Comisión Diocesana de Música Sacra de la diócesis de Zacatecas.

Francisco Aguilar y Urízar (1867-1948), pianista, chelista y compositor, no sólo es conocido por su faceta como músico, sino como matemático, ya que a los quince años ingresó en el Instituto de Ciencias de Zacatecas; sin embargo, abandonó enseguida sus estudios de ciencias por la música. Como músico, en 1890 debutó integrado en un grupo en una función de beneficencia; en 1893 actuó ya como solista en el Teatro Calderón, interpretando la Marcha de las antorchas, del compositor alemán Meyerbeer. En 1897, ingresó como maestro de piano a la Escuela Normal. Más tarde, en 1901, regresó al campo científico, al iniciar estudios de ingeniería topográfica, que compaginó con su trabajo de profesor de música e intérprete. Aunque su obra es breve, en ella destacan un Ave María, para soprano y orquesta, y la romanza Aurora, para soprano y sexteto de cuerdas. Junto al compositor Julián Barrón, musicalizó dos autos sacramentales: Del pan y del palo, de Lope de Vega, y La amistad en peligro, de Valdivieso, ambos estrenados en la ciudad de Zacatecas en 1924.

Julián Barrón (1879-1941), natural de Veta Grande, fue cantor en la parroquia de la localidad de Pánuco, y cantor y organista en la de Santo Domingo, en la capital Zacatecana. Además de interpretar música sacra, organizó también varias orquestas típicas. Entre sus obras destaca el fox-trot Cine de Barrio, pensada para proyecciones de cine mudo en el "Salón Azul, la danza para piano Emilia, dedicada a su alumna, la señorita Emilia Saldívar, el tango Imposible, partitura escrita para la Revista Telegráfica, el vals para piano Hasta el cielo y la pequeña pieza El Piquín. Sus obras, editadas al igual que las de Severiano González, otro distinguido compositor local, en la ya citada imprenta de Don Nazario Espinosa, fueron muy populares en su época, gozando del favor del público.

Manuel M. Ponce (1882-1948), pianista y compositor nacido en Fresnillo, es, junto a Villalpando y Codina, el tercer gran exponente de la música zacatecana y el que mayor reconocimiento ha tenido a nivel mundial. Desde temprana edad recibió clases de piano de su hermana Josefina, y en 1897 ya fue organista del templo de San Diego de Aguascalientes.
En 1900, ingresó al Conservatorio Nacional de Música de Ciudad de México, institución de la que después sería profesor. Cuatro años más tarde viajó a Italia para estudiar en el Liceo Musical de Bolonia. Posteriormente, viajó por Alemania y Cuba, y en 1918 fue designado director de la Orquesta Sinfónica de México. En su interés por vincular la música folclórica mexicana con los estilos europeos del momento, en 1925 fue a París, donde permaneció ocho años. A su regreso a México fundó revistas, escribió artículos y ensayos, dirigió la Escuela Nacional de Música de la UNAM, compuso música para la mayoría de instrumentos, para cámara, orquesta y especialmente para guitarra. Entre sus numerosas composiciones de música de salón destacan las canciones Estrellita, La pajarera, Lejos de ti, Cuiden su vida, Si alguna vez, Qué lejos ando, Si algún ser, Yo mismo no comprendo, Isaura de mi amor, Por ti mi corazón, Soñó mi mente loca, Tú, Aleluya, Cerca de ti y un largo etcétera. A decir del musicólogo español Otto Mayer-Serra, Ponce es el más destacado representante del moderno nacionalismo musical mexicano (Mayer-Serra, 1941, p. 75).

Octaviano Sigala Gómez (1892-1957) es originario de Nochistlán. En 1930, el gobernador de Zacatecas, Luis R. Reyes, le encargó la organización y la dirección de la Banda de Música del Estado y Municipio de Zacatecas. Entre sus obras, es especialmente conocido el vals para piano Merceditas, compuesto en 1950 por encargo de su amigo, Don Carlos Zorrilla Enciso, para regalárselo a su esposa en su onomástica; esta pieza fue instrumentada para ser interpretada por el maestro invidente Félix González Hidalgo, músico muy admirado por el público zacatecano.

Severiano González Delgado (18931985) nació en Villanueva, pero desde muy pequeño se trasladó a la capital del Estado, donde estudió música con su hermano Magdaleno y el señor canónigo J. Anastasio Díaz López. En 1904, ingresó como alumno de la Escuela de Música Religiosa, y más tarde se desempeñó como cantor y organista en varios templos de la ciudad, llegando a ser maestro de capilla de la Catedral zacatecana. En 1918, compuso el himno a Nuestra Señora de los Zacatecas, dedicado al Ilmo. Rmo. Señor Obispo Doctor Don Miguel M. de la Mora. 
Entre su música de salón destaca $A m i$ madre pequeña serenata, compuesta en 1918, con letra de su hermana María y dedicada "Al inspirado compositor Sr. D. Julián Barrón y Soto como un testimonio del afecto íntimo que le profeso".

Isauro Félix Berumen (1898-1987) estudió Humanidades y Filosofía en el Seminario Conciliar de Zacatecas y música en la misma ciudad con el maestro Arnulfo Miramontes. En el Instituto de Ciencias de Zacatecas, actual Universidad Autónoma de Zacatecas, fue maestro de español, latín y griego, etimologías grecolatinas y cultura musical. Durante cuarenta y dos años fue organista de la parroquia de Santo Domingo. Compuso varias piezas musicales para piano y coro y otras de géneros diversos, como su Vals no. 2, allegro scherzando, que puede ser considerada ya una obra contemporánea, tanto en su concepción musical como en su trabajo armónico. La mayoría de las obras aquí aludidas, en un esfuerzo de recuperación del patrimonio musical zacatecano, fueron arregladas o transcritas para ensambles de cámara (tríos, cuartetos, etc.) y grabadas en Zacatecas por iniciativa del Ensamble Clásico de Zacatecas, en los discos compactos Música de Salón, Joyas musicales de Zacatecas y Música Latinoamericana ${ }^{7}$.

\section{Conclusión}

Los compositores anteriores de cuna zacatecana, brevemente enumerados, y muchos otros no citados, pertenecen a una misma generación que intentó conciliar una nueva música, nacionalista y folklorista, como una forma de expresión de identidad cultural propia y libertad creativa, con las nuevas propuestas técnicas y estéticas aparecidas en Europa. Al mismo tiempo, pretendieron inútilmente liberarse de la música de salón sin conseguirlo, ya que, durante muchos años las obras de esta naturaleza fueron aplaudidas y demandadas por el público, y los autores debieron rendirse a la evidencia de que el gusto por lo salonesco no había desaparecido en una Zacatecas que todavía iba a remolque de los dictados capitalinos y extranjeros, tal y como se evidencia en las numerosas obras compuestas por todos y cada uno de los mencionados, adheridas todavía a esta tradición de cuño romántico.

\footnotetext{
${ }^{7}$ Dos de las coautoras de este trabajo, Mara Lioba-Juan Carvajal y María Vdovina, son fundadoras e integrantes del citado ensamble.

La literatura nos acerca a la honda impresión que en las sensibilidades zacatecanas dejaba esta música paradójica, generada en la intimidad de los hogares y, además, tremendamente popular en la calle: El 20 de octubre de 1913, Ramón López Velarde, bajo el seudónimo de Tristán, escribe en el periódico potosino El Eco de San Luis una reflexión poético-musical en prosa, que titula "En alas de la música”, en el más puro estilo romántico y modernista:

[...] contra el bochorno, las nubes y la oscuridad hay una sabia orquesta que nos baña de placidez y de luz mágica. Hay magia en la sutileza de los violines y magia en las graves flautas. Tiene alma de música la tarde gris y nos vamos elevando a regiones de ensueño, sobre las alas de una melodía que nos mece en una cuna lírica... Elevémonos y soñemos.

[...] El don de la armonía que nos trae, de muy lejos, las caricias de la voz de una mujer, vale un poco de sangre para que se mojen los antiguos dardos. Oír música y pensar en la amada... iqué importa que sangremos!

Flautas y violines van esparciendo las notas de un vals, que ondula como para marearnos y embriagarnos. El vals se exalta, a las veces, en arranques súbitos y a las veces con languidez, como si rebosara de felicidad y la felicidad lo agotase (López Velarde, 2013, pp. 41 y 42 ).

Todas estas emociones, expresadas en lenguaje poético, eran provocadas por una música de salón, cuyos compositores, pese a que no todos tenían el mismo grado de avance técnico, se caracterizaban por compartir una misma ideología romántica. En opinión de Otto Mayer "Se comprende que las inquietudes del siglo romántico no les eran ajenas, pero que aún no disponían de los medíos musicales para expresarlas en su arte" (Mayer-Serra, $1941 \mathrm{p}$. 85). Sin embargo, resultan encomiables los intentos de los creadores zacatecanos de este tiempo por intentar zafarse de siglos de tradición e influencias culturales importadas, para lograr expresarse con personalidad propia. No en vano ellos constituyeron el puente definitivo entre un pasado musical forzado y un presente propio $\mathrm{y}$ distintivo. 


\section{Referencias}

Alonso González, Celsa (1993). “Los salones: un espacio musical para la España del siglo XIX", Anuario Musical, No. 48. Madrid: CSIC, pp. 165-206.

Carreras, Juan José (Ed.) (2018). Historia de la música en España e Hispanoamérica, Vol. 5. Madrid: FCE.

Casares Rodicio, Emilio y Celsa Alonso González (1995). La música española en el siglo XIX. Oviedo: Universidad de Oviedo.

Collard, Patrick (2012). "Le Romantisme Ibéroaméricain". Dictionnaire du Romantisme, (Dir. Alain Vaillant). París: CNRS, pp. 1-8. En línea: https://core.ac.uk/download/pdf/55810243.pdf, Consultado: 30 de julio de 2020.

Daumard, Adeline (1986). "La vie de salon en France dans la première moitié du XIX siècle", Sociabilité et société bourgeoise en France, en Allemagne et en Suisse, 1750-1850, (Ed. Étienne François). París: Recherche sur les Civilisations, pp. 81-93.

Díaz Santana, Luis (2009). Tradición musical en Zacatecas. Una historia socio-cultural (18501930). Zacatecas: Instituto Zacatecano de Cultura "Ramón López Velarde".

Díez Huerga, María Aurelia (2009). "Salones, bailes y cafés: costumbres socio-musicales en el Madrid de la reina castiza (1833-1868)", Anuario Musical, No. 61. Madrid: CSIC, pp. 189-210.

Espinosa Orozco, Alberto (2018). "Breve Historia de la Litografía en México: La Época de Oro de la Litografía en México y en Zacatecas", Terranova. En línea: http://terranoca.blogspot.com/2018/09/laepoca-de-oro-de-la-litografia-en.html. Consultado: 30 de julio de 2020.

Fernández de Córdova, Fernando (1886). Mis memorias intimas. Madrid: Establecimiento tipográfico Sucesores de Rivadeneyra.

Gutiérrez Hernández, Norma (2013). Mujeres que abrieron camino. La educación femenina en la ciudad de Zacatecas durante el Porfiriato. Zacatecas: Universidad Autónoma de Zacatecas. López Velarde, Ramón (1994). Obras, (Comp. José Luis Martínez). México: FCE.
(2013). Renglones líricos y

El obsequio de Ponce. San Luis Potosí: Gobierno del Estado de San Luis PotosíCONACULTA.

Mayer-Serra, Otto (1941). Panorama de la Música Mexicana. México: El Colegio de México.

Moreno Rivas, Yolanda (1995). Rostros del nacionalismo en la música mexicana. Un ensayo de interpretación. México: Escuela Nacional de Música. La Música en México durante el siglo XIX. En línea: https://musicaenlahistoriamx.wordpress.com/20 11/12/13/34. Consultado: 30 de julio de 2020.

Palacios Sanz, José Ignacio y Ricardo Martín de la Guardia (2017). "Casinos y espacios de recreo para la música: el caso de la ciudad de Soria (1848-1936)", Studia Historica. Historia Contemporánea, No. 35. Salamanca: Ediciones Universidad de Salamanca, pp. 317-338.

Recasens Barberà, Albert (2010). A tres bandas. Mestizaje, sincretismo e hibridación en el espacio sonoro iberoamericano. Madrid: Akal.

Romero, Jesús C. (1963). La música en Zacatecas y los músicos zacatecanos. México: UNAM.

Schenk, H. G. (1983). El espíritu de los románticos europeos. México: FCE.

VV.AA. (1996). El Teatro Calderón, protagonista de piedra. Zacatecas: Universidad Autónoma de Zacatecas. 